\title{
Family Structure and Psychological Health in Young Adults
}

\author{
Tony Cassidy, Elizabeth Wright, Elizabeth Noon \\ University of Ulster, Coleraine, UK \\ Email: t.cassidy@ulster.ac.uk, l.wright@dmu.ac.uk, enoon@dmu.ac.uk
}

Received 16 June 2014; revised 11 July 2014; accepted 5 August 2014

Copyright (C) 2014 by authors and Scientific Research Publishing Inc.

This work is licensed under the Creative Commons Attribution International License (CC BY). http://creativecommons.org/licenses/by/4.0/

c) (i) Open Access

\section{Abstract}

This study explored the effect of the gendered structure of siblings in intact and non-intact families, on family relations, social support, perceived control, and psychological distress in a sample of 708 young adults (294 males and 414 females) aged between 18 - 21 years. Of the sample 96 were singletons, 208 had both a brother and sister, 206 had a brother and no sister, and 198 had a sister and no brother. While the results show that both the gender of the participants and the gender of the sibling seem to impact on distress and its mediators; the more important factor is the gender of siblings. In essence the presence of a female sibling is associated with more perceived support, control and optimism, and with lower pessimism and psychological distress. The presence of a female is also associated with better family relations overall and it is suggested that the main mechanism for this positive impact of female siblings is through the lowered conflict and increased expressiveness and cohesion experienced in female versus male dominated sibling groups.

\section{Keywords}

Gender, Siblings, Family Structure, Psychological Health

\section{Introduction}

Young adults who experienced parental divorce continue to have poorer outcomes than young adults in continuously intact two parent families (Cherlin, Kiernan, \& Chase-Lansdale, 1995). However the negative impact seems to disappear when other factors, such as socioeconomic status of the family following break up, are taken into account (Biblarz \& Raftery, 1999). Simply knowing a child's living arrangements tells us little about the family environment in which they reside and comparing outcomes of children in intact and single-parent homes neglect the complexities of family life (Videon, 2002). Indeed when marital conflict is intense, separation re- 
moves children from this high conflict environment, improving their well-being (Amato, Loomis, \& Booth, 1995). This highlights circumstances in which parental separation is beneficial for children's well-being, raising questions about whether it is a problematic family environment that affects children's well-being rather than residential separation from a parent. In fact in Biblarz and Raftery's (1999) review there is evidence that in some cases children can benefit from being raised in a single-sex maternal family rather than any other combination, an effect which is best explained in terms of evolutionary parental investment theory.

Investigations of non-intact families frequently find that effects are mediated or moderated by parent-child relations and any consideration of the gendered nature of family structure has focused on the sex of the parent and child. Drawing on the fact that the majority of children live with their mothers after marital dissolution, researchers have suggested that boys' more negative outcomes in response to parental divorce could be explained by the absence of a same-sex parent.

Research has ignored the importance of inter-sibling relationships despite evidence that they are an important source of emotional support during family transitions or dissolution (Dunn, 1996; Bryant, 1992). An increasing interest in the family as an "agent of change" (Brody, 1998) has encouraged researchers to investigate dynamic processes in sibling relationships. Bank and Kahn (1976) argue that "sibling relationships lay the ground work for developing peer and other intimate relationships, and are important to the development of self-esteem and self-concept". The nature and quality of sibling interaction has been related to children's social adjustment at school, (Stormshak, Bellanti, \& Bierman, 1996), and the development of social-cognitive skills such as affective perspective taking and consideration of other people’s feelings and beliefs (Brown \& Dunn, 1992).

There is evidence of sex differences in cohesion and conflict between siblings, with males being associated with more conflict and lower levels of cohesion (Weiss, Schitaffino, \& Ilowite, 2001). Similarly, there is some evidence that families with female siblings tend to be related to more expressive family environments and that this may, in turn, impact on coping and health (Cassidy \& Newport, 1996). It is well recognized that the combination of high levels of conflict and less cohesive family emotional environments are associated with more negativity in sibling relationships (Brody, Stoneman, \& McCoy, 1994). However, since studies involving siblings have generally focused on the quality of the sibling relationship, it is perhaps less well recognized that sibling relationships and the gender combination of the siblings are themselves significant contributors to the family environment. Given the potential impact of sex on sibling interactions, and therefore the family environment, one might predict that sibling sex structure has an impact on psychological health. Considering the evidence that the quality of interaction between siblings might mediate the impact of parental absence and given the suggestion that the gender structure of siblings is related to sibling interaction, it is reasonable to suggest that the gender structure of single parent families might be related to health outcomes for the children.

Research on psychosocial processes in both physical and psychological health has identified a number of mediating and moderating variables of which the most widely established are social support (Sarason, Sarason \& Pierce, 1993), perceived control (Krause \& Stryker, 1984), and optimism (Cassidy, 1999). In terms of social support, it is well established in the literature that it is the perception of support that is important and that perceived support provides a buffer against life stress in all its forms and across all ages (Pretorius \& Diedricks, 1994). Families provide a major source of social support and there is some evidence for the efficacy of sibling support during family difficulties (Dunn, 1996). Perceived control tends to equate with an internal locus of control in the literature and again it has been widely established that the perception of control reduces the impact of life stress (Cassidy, 1999). Power and control has been investigated within the systems model of family therapy and is considered one of three main dimensions with inclusion and emotional proximity in family problems. The role of control in relation to family structure and in particular sibling interaction seems to have been neglected. Optimism and pessimism (or hopelessness) has been a source of substantial debate in the literature and it is now generally agreed that they are separate dimensions rather than two opposing ends of a single dimensions as was assumed by most early research such as Beck (1981). Optimism is well established as a buffer against life stress and a contributing factor in positive health and well-being, while pessimism is seen as a major risk factor in depression and generally contributing to psychological illness. Again, despite the importance of optimism and pessimism in the psychological process of health and illness, it has not been widely researched in relation to family structure and sibling relations.

Clearly family factors are important in the psychological health of children and young adults but the role of inter-sibling relations is not very well understood. The current study was inspired by an incidental finding in a 
study by Cassidy and Newport (1998) which suggested that in non-traditional families, the effects on psychological well-being and family relationships might be mediated by the gender structure of the remaining siblings. In effect girls in an all girl non-traditional family reported more cohesion, expressiveness and encouragement to achieve than girls in traditional families, with the effect being reversed for boys. The current paper describes a study which looks at the relationship between the gender structure of families and a range of other variables; family environment, social support, optimism, pessimism, locus of control, and psychological distress.

The research questions addressed are:

1) Does the gender structure of siblings in the family impact on later psychological or physical health as an adult?

2) In what way is gender structure of siblings in the family related to later psychological or physical health as an adult?

3) Does gender structure of siblings in the family moderate the impact of parent presence or absence on later psychological or physical health as an adult?

\section{Method}

\subsection{Design}

This study used a quasi-experimental survey design with questionnaire data collection methods, to explore the effect of the gendered structure of siblings in intact and non-intact families, on family relations, social support, perceived control, and psychological distress.

\subsection{Participants}

The sample was 708 participants (294 males and 414 females), aged 18 - 21 years old, selected from random groups of social science and humanities undergraduate students. Quota sampling was used to ensure representative numbers of males and females and intact $(\mathrm{N}=289)$ versus non-intact $(\mathrm{N}=419)$ home backgrounds. In the sample 96 were singletons, 208 had both a brother and sister, 206 had a brother and no sister, and 198 had a sister and no brother.

\subsection{Materials}

A variety of information was gathered from participants including age, gender, whether their childhood home was intact or if parents had split up, the age at which this had occurred, and the level of contact they had had with the absent parent.

In addition participants were assessed on the following measures:

1) The Locus of Control of Behaviour Scale (Craig, Franklin, \& Andrews, 1984). This is a 17 item scale which produces a score of perceived locus of control of behaviour. The scales are scored so that the higher score indicates an internal locus of control.

2) The Life Orientation Test (LOT) (Scheier \& Carver, 1985). This is a fourteen item scale which produces a measure of dispositional optimism. The scale is scored so that high scores indicate high dispositional optimism.

3) The Social Support Scale (Cassidy \& Burnside, 1996). This is a 12-item measure of perceived social support. A higher score indicates more support. The scale has a Cronbach Alpha of 0.89 in this study.

4) The Family Environment Scale (Moos \& Moos, 1986). This is a 90 item scale which measures 10 first order factors of family environment, cohesion, expressiveness, conflict, independence, achievement orientation, intellectual-cultural orientation, active-recreational orientation, moral-religious orientation, organisation and control. The scales are scored so that a higher score indicates more experience of the specific factor within the family. The 10 first order factors can be grouped into 3 second order factors, a) family relations (cohesion, expressiveness, and conflict), b) personal growth (independence, achievement orientation, intellectual-cultural orientation, active-recreational orientation, and moral-religious orientation), and c) systems maintenance (organisation and control).

5) The General Health Questionnaire (12-item version) (GHQ-12) (Goldberg, 1972). This is a widely used measure of psychological distress combining depression, anxiety and somatisation. Higher scores indicate more psychological distress. 


\subsection{Procedure}

Participants were selected from random groups of social science and humanities undergraduate students using quota sampling based on an age range of 18 - 21, equal numbers of males and females, and equal numbers from intact versus non-intact home backgrounds. All participants were assured of anonymity and that participation was voluntary.

\section{Results}

The primary purpose of the current study was to test the hypothesised relationship between the gendered structure of siblings in intact and non-intact families, in terms of family environment, social support, perceived control, optimism, and psychological health. The first stage of analysis used a Multivariate analysis of variance (Manova) with gender, intact versus non-intact homes, and number of siblings as the three independent variables and psychological distress, optimism, pessimism, locus of control, social support and the family environment dimensions of family relations, systems maintenance, and personal growth as the dependant variables. The means and standard deviations for this analysis are shown in Table 1.

There were main effects for gender on social support $(\mathrm{F}(1,706)=29.89, p<.001)$, locus of control $(\mathrm{F}(1,706)$ $=4.34, p<.05)$, optimism $(\mathrm{F}(1,706)=23.23, p<.001)$, personal growth $(\mathrm{F}(1,706)=28.99, p<.001)$, and systems maintenance $(\mathrm{F}(1,706)=16.01, p<.001)$. Females scored higher on social support, optimism, personal growth and systems maintenance and lower on locus of control than males (see Table 1).

There were main effects for intact versus non-intact homes on optimism $(\mathrm{F}(1,706)=10.96, p<.001)$ pessi$\operatorname{mism}(\mathrm{F}(1,706)=10.23, p<.001)$, locus of control $(\mathrm{F}(1,706)=20.16, p<.001)$, family relations $(\mathrm{F}(1,706)=$ 8.16, $p<.001)$, personal growth $(\mathrm{F}(1,706)=35.39, p<.001)$ and systems maintenance $(\mathrm{F}(1,706)=43.95, p$ $<$.001). Participants from non-intact homes scored higher on both optimism and pessimism, social support, locus of control, and but lower on family relations, personal growth and systems maintenance.

The variable "sibling structure" had four levels, no siblings, brother only, sister only, and both brother and sister. There were main effects for sibling structure on psychological distress $(\mathrm{F}(3,706)=34.39$, $p<.001)$, optimism $(\mathrm{F}(3,706)=133.70, p<.001)$, pessimism $(\mathrm{F}(3,706)=23.18, p<.001)$, locus of control $(\mathrm{F}(3,706)=$ $15.68, p<.001)$, social support $(\mathrm{F}(3,706)=30.63, p<.001)$, family relations $(\mathrm{F}(3,706)=8.28, p<.001)$, systems maintenance $(\mathrm{F}(3,706)=6.78, p<.001)$, and personal growth $(\mathrm{F}(3,706)=14.55, p<.001)$. Post Hoc analysis (LSD) identified where the significant effects occurred. Only children scored significantly lower than any other category on psychological distress. Participants who have a brother scored significantly higher on psychological distress. Participants with sisters scored significantly higher than all other categories on optimism, and family relations. Only children and participants with sisters scored significantly lower on pessimism, and

Table 1. Means and standard deviations for independent variables categorized by sex and family structure.

\begin{tabular}{cccccccccc}
\hline & \multicolumn{3}{c}{ Sex } & \multicolumn{9}{c}{ Family structure } & \multicolumn{3}{c}{ Sibling structure } \\
\cline { 2 - 9 } Variable & Male & Female & Broken Home & Intact home & Only child & Brother (s) & Sister (s) & Both \\
& $\mathrm{N}=294$ & $\mathrm{~N}=414$ & $\mathrm{~N}=289$ & $\mathrm{~N}=419$ & $\mathrm{~N}=96$ & $\mathrm{~N}=206$ & $\mathrm{~N}=198$ & $\mathrm{~N}=208$ \\
\cline { 2 - 10 } & Mean (Sd) & Mean (Sd) & Mean (Sd) & Mean (Sd) & Mean (Sd) & Mean (Sd) & Mean (Sd) & Mean (Sd) \\
\hline \multirow{2}{*}{ Distress } & $14.62(6.86)$ & $13.98(6.59)$ & $13.87(6.74)$ & $14.51(6.67)$ & $12.97(5.16)$ & $17.45(7.40)$ & $11.37(4.24)$ & $14.40(7.14)$ \\
Social support & $22.52(7.10)$ & $25.60(7.61)$ & $24.96(7.40)$ & $23.88(7.63)$ & $25.38(6.32)$ & $20.48(7.42)$ & $28.43(7.96)$ & $23.74(5.46)$ \\
Locus of control & $10.32(6.38)$ & $9.41(5.26)$ & $10.94(5.29)$ & $8.99(5.94)$ & $7.61(3.41)$ & $8.50(5.23)$ & $10.85(6.80)$ & $11.05(5.52)$ \\
Optimism & $12.97(4.35)$ & $14.75(5.16)$ & $14.74(4.51)$ & $13.50(5.12)$ & $12.54(2.19)$ & $10.17(3.07)$ & $18.81(4.35)$ & $13.91(3.90)$ \\
Pessimism & $12.59(5.92)$ & $12.21(6.09)$ & $13.05(5.99)$ & $11.89(6.01)$ & $9.66(3.42)$ & $14.96(5.04)$ & $10.45(6.39)$ & $12.89(6.37)$ \\
Family relationship & $9.36(5.66)$ & $9.43(7.37)$ & $8.54(7.29)$ & $9.99(6.21)$ & $9.23(6.48)$ & $8.41(5.90)$ & $11.12(7.96)$ & $8.82(5.95)$ \\
Personal growth & $22.52(9.49)$ & $26.66(10.46)$ & $22.22(7.35)$ & $26.79(11.51)$ & $29.45(10.29)$ & $21.68(9.59)$ & $26.38(11.74)$ & $24.75(8.21)$ \\
Systems maintenance & $8.58(4.69)$ & $10.19(5.62)$ & $7.97(5.12)$ & $10.59(5.18)$ & $10.71(5.43)$ & $8.84(5.71)$ & $10.43(5.15)$ & $8.78(4.78)$ \\
\hline
\end{tabular}


higher on personal growth, systems maintenance and social support than any other category. Only children and participants with a brother only had a significantly stronger external locus of control than the other categories, while those with a sister only or both brothers and sisters had a significantly stronger internal locus of control. Participants with a sister scored significantly higher on family relationship than those with a brother.

There was a significant interaction between gender and intact/non-intact homes on psychological distress $(\mathrm{F}(1$, $706)=8.98, p<.01)$, locus of control $(\mathrm{F}(1,706)=8.58, p<.01)$, and personal growth $(\mathrm{F}(1,706)=21.21, p$ $<.001)$. There were significant interaction effects between gender and sibling structure on psychological distress $(\mathrm{F}(1,706)=3.97, p<.01)$, optimism $(\mathrm{F}(1,706)=7.08, p<.001)$, locus of control $(\mathrm{F}(1,706)=3.54, p<.01)$, and family relations $(\mathrm{F}(1,706)=2.61, p<.05)$.

In order to explore the location of significant effects a gender by sibling structure variable was computed, the means for which are shown in Table 2. This gender by sibling structure variable had 8 levels, boy with no siblings, girl with no sibling, boy with brother only, girl with brother only, boy with sister only, girl with sister only, boy with both brother and sister, and girl with both brother and sister.

One way analysis of variance (Anova) was used to identify main effects on this variable. Main effects for gender by sibling structure were identified on psychological distress $(\mathrm{F}(7,700)=16.31, p<.001)$, optimism $(\mathrm{F}(7,700)=91.61, p<.001)$, pessimism $(\mathrm{F}(7,700)=10.53, p<.001)$, locus of control $(\mathrm{F}(7,700)=8.50, p$ $<.001)$, social support $(\mathrm{F}(7,700)=24.18, p<.001)$, family relations $(\mathrm{F}(7,700)=4.32, p<.001)$, systems maintenance $(\mathrm{F}(7,700)=7.15, p<.001)$, and personal growth $(\mathrm{F}(7,700)=10.93, p<.001)$. Post Hoc analysis (LSD) identified where the significant effects occurred. Boys with a brother scored significantly higher than any other category on psychological distress. Only children and boys with a sister scored lowest on psychological distress. Boys with a sister, girls with a sister, and girls with both scored significantly higher than other categories on optimism. The least optimistic participants were girls with brothers. Boys with brothers, girls with brothers, and girls with both brothers and sisters scored highest on pessimism. The lowest scores on social support were boys with brothers and girls with brothers. The highest scores on social support were girls with sisters, girls with both brothers and sisters, or only girls. Boys with sisters, boys with both brothers and sisters, and girls with sisters had a significantly higher internal locus of control. Boys with brothers, girls with brothers, and only boys had significantly higher external locus of control. Boys with sisters, and girls with sisters scored highest on family relationship, girls with brothers, and only girls scored lowest. Boys with brothers, boys with sisters, and girls with brothers scored lowest on personal growth. Boys with sisters and girls with sisters scored highest on systems maintenance.

A Multivariate analysis of variance (Manova) was used to test for interaction effects between gender by sibling structure (the variable computed for the previous analysis) and intact/non-intact homes on all the other variables. There were significant interaction effects on psychological distress $(\mathrm{F}(7,700)=4.30, p<.001)$, opti$\operatorname{mism}(\mathrm{F}(7,7 \mathrm{~F}(7,704)=4.30, p<.001)=6.55, p<.001)$, pessimism $(\mathrm{F}(7,700)=3.17, p<.01)$, social support $(\mathrm{F}(7,700)=4.59, p<.001)$, locus of control $(\mathrm{F}(7,700)=4.49, p<.001)$ family relations $(\mathrm{F}(7,700)=11.03, p$ $<.001)$, systems maintenance $(\mathrm{F}(7,700)=3.82, p<.001)$, and personal growth $(\mathrm{F}(7,700)=6.08, p<.001)$. The means and standard deviations for this analysis are shown in Table 3.

As can be seen in Table 3 the levels of psychological distress were consistently higher for participants from broken homes except for boys with sisters, and boys with both brothers and sisters, where the reverse was true. The highest levels of psychological distress were observed in boys with brothers from broken homes. Lowest levels of psychological distress were observed in only girls from intact homes, followed by boys with a sister from broken homes, and only boys from intact homes. Perceived social support was higher for all participants whose parents had split up, except for only girls. The highest scores were for only girls in intact families, followed by boys and girls with sisters in broken homes. The highest scores for optimism were observed in girls with sisters from intact homes, and the highest scores for pessimism were observed in boys with brothers from broken homes.

The highest score on the family relationship dimension of the Family Environment Scale was for girls with sisters in intact homes. For the systems maintenance dimension the highest scores were observed in boys and girls with sisters in intact homes. The lowest scores were observed in boys with brothers from broken homes, and only boys from broken homes. The lowest scores on the personal growth dimension were observed in boys with brothers from intact homes, and the highest scores were observed in boys with brothers from broken homes.

Because the impact of sibling structure on the family environment was a key focus and the Family Environ- 
Table 2. Means and standard deviations for independent variables categorised by sibling sex structure.

\begin{tabular}{ccccccccc}
\hline \multirow{2}{*}{ Variable } & $\begin{array}{c}\text { Only girl } \\
\mathrm{N}=49\end{array}$ & $\begin{array}{c}\text { Only boy } \\
\mathrm{N}=44\end{array}$ & $\begin{array}{c}\text { Girl with } \\
\text { brother } \\
\mathrm{N}=104\end{array}$ & $\begin{array}{c}\text { Boy with } \\
\text { brother } \\
\mathrm{N}=102\end{array}$ & $\begin{array}{c}\text { Girl with } \\
\text { sister } \\
\mathrm{N}=128\end{array}$ & $\begin{array}{c}\text { Boy with } \\
\text { sister } \\
\mathrm{N}=70\end{array}$ & $\begin{array}{c}\text { Girl with } \\
\text { both }\end{array}$ & $\begin{array}{c}\text { Boy with } \\
\text { both }\end{array}$ \\
\cline { 2 - 9 } & Mean (Sd) & Mean (Sd) & Mean (Sd) & Mean (Sd) & Mean (Sd) & Mean (Sd) & Mean (Sd) & Mean (Sd) \\
\hline Distress & $13.69(5.65)$ & $12.14(4.42)$ & $16.11(7.82)$ & $18.81(6.72)$ & $11.93(4.02)$ & $10.34(4.48)$ & $14.42(7.29)$ & $14.38(6.91)$ \\
Social support & $26.46(7.61)$ & $24.09(4.06)$ & $21.02(7.19)$ & $19.92(7.65)$ & $29.36(7.94)$ & $26.73(7.78)$ & $25.23(5.25)$ & $21.24(4.88)$ \\
Locus of control & $7.71(3.62)$ & $7.50(3.20)$ & $7.97(4.56)$ & $9.04(5.89)$ & $10.72(6.21)$ & $11.09(7.81)$ & $9.94(4.99)$ & $12.89(5.89)$ \\
Optimism & $12.37(2.40)$ & $12.75(2.17)$ & $10.28(3.11)$ & $10.05(3.05)$ & $19.60(4.17)$ & $17.36(4.31)$ & $14.49(4.02)$ & $12.96(3.51)$ \\
Pessimism & $9.36(3.68)$ & $10.02(3.10)$ & $14.35(5.14)$ & $15.57(4.87)$ & $11.22(6.94)$ & $9.03(4.99)$ & $12.61(6.07)$ & $13.35(6.85)$ \\
Family relationship & $10.65(6.14)$ & $7.57(6.54)$ & $7.37(7.16)$ & $9.47(4.03)$ & $11.20(9.47)$ & $10.98(3.99)$ & $8.85(4.72)$ & $8.77(7.61)$ \\
Personal growth & $30.04(10.07)$ & $28.79(10.61)$ & $23.86(9.79)$ & $19.45(8.90)$ & $28.13(12.17)$ & $23.19(10.24)$ & $26.19(8.64)$ & $22.38(6.85)$ \\
Systems maintenance & $9.71(4.85)$ & $11.89(5.89)$ & $10.13(6.48)$ & $7.51(4.44)$ & $11.05(5.63)$ & $9.31(3.94)$ & $9.57(5.11)$ & $7.46(3.87)$ \\
\hline
\end{tabular}

Table 3. Means and standard deviations for dependent variables categorised by gender by sibling structure, and intact/broken homes.

\begin{tabular}{|c|c|c|c|c|c|c|c|c|c|}
\hline \multirow{2}{*}{$\begin{array}{l}\text { Gender by } \\
\text { sibling } \\
\text { structure }\end{array}$} & \multicolumn{9}{|c|}{ Variables } \\
\hline & $\begin{array}{l}\text { Intact/ } \\
\text { Broken home }\end{array}$ & $\begin{array}{l}\text { Psychological } \\
\text { distress }\end{array}$ & $\begin{array}{l}\text { Social } \\
\text { support }\end{array}$ & $\begin{array}{l}\text { Locus of } \\
\text { control }\end{array}$ & Optimism & Pessimism & $\begin{array}{l}\text { Family } \\
\text { relationship }\end{array}$ & $\begin{array}{l}\text { Personal } \\
\text { growth }\end{array}$ & $\begin{array}{c}\text { Systems } \\
\text { maintenance }\end{array}$ \\
\hline \multirow[b]{2}{*}{ Only girl } & Parents split $(\mathrm{N}=27)$ & $12.63(4.07)$ & $27.85(7.66)$ & 9.07 (3.96) & $12.52(1.97)$ & $9.23(3.31)$ & $12.41(5.81)$ & $26.56(9.54)$ & $7.78(4.02)$ \\
\hline & $\begin{array}{l}\text { Parents together } \\
\qquad(\mathrm{N}=25)\end{array}$ & $14.84(6.88)$ & $24.96(7.41)$ & $6.24(2.54)$ & $12.20(2.83)$ & $9.50(4.10)$ & $8.76(6.02)$ & 33.67 (9.49) & $11.80(4.86)$ \\
\hline \multirow[b]{2}{*}{ Only boy } & Parents split $(\mathrm{N}=14)$ & 10.57 & 25.00 (3.59) & $8.14(4.62)$ & $11.64(1.60)$ & $10.86(2.18)$ & $11.43(3.08)$ & $27.43(10.60)$ & $7.29(5.14)$ \\
\hline & $\begin{array}{l}\text { Parents together } \\
\qquad(\mathrm{N}=30)\end{array}$ & 12.87 (4.79) & $23.67(4.25)$ & $7.20(2.31)$ & $13.10(2.26)$ & $9.63(3.41)$ & 5.77 (6.98) & $29.43(10.74)$ & $14.03(4.96)$ \\
\hline \multirow{2}{*}{$\begin{array}{l}\text { Boy with } \\
\text { brother }\end{array}$} & Parents split $(\mathrm{N}=21)$ & $19.10(5.01)$ & 21.05 (7.99) & $7.33(6.51)$ & $11.11(1.79)$ & $14.01(4.65)$ & $5.80(7.16)$ & $22.53(2.43)$ & 7.33 (3.48) \\
\hline & $\begin{array}{l}\text { Parents together } \\
\qquad(\mathrm{N}=81)\end{array}$ & $18.74(7.12)$ & $19.63(7.58)$ & 9.48 (5.69) & 9.78 (3.25) & $15.98(4.88)$ & $10.42(1.80)$ & 18.65 (9.77) & 7.56 (4.68) \\
\hline \multirow{2}{*}{$\begin{array}{l}\text { Girl with } \\
\text { brother }\end{array}$} & Parents split ( $\mathrm{N}=37)$ & $17.86(9.52)$ & $23.02(8.47)$ & 8.95 (4.07) & $10.73(2.87)$ & $14.96(5.34)$ & 3.36 (6.77) & $19.25(5.71)$ & 7.19 (5.99) \\
\hline & $\begin{array}{l}\text { Parents together } \\
\qquad(\mathrm{N}=67)\end{array}$ & $15.13(6.58)$ & $19.91(6.18)$ & $7.43(4.60)$ & $10.03(3.22)$ & $14.01(5.04)$ & $9.59(6.40)$ & $26.41(10.64)$ & $11.76(6.20)$ \\
\hline \multirow{2}{*}{$\begin{array}{l}\text { Boy with } \\
\text { sister }\end{array}$} & Parents split $(\mathrm{N}=17)$ & $8.47(3.02)$ & 24.85 (8.68) & $8.47(6.00)$ & $15.35(3.50)$ & 10.82 (5.69) & 7.48 (3.59) & $22.55(7.06)$ & $9.06(5.65)$ \\
\hline & $\begin{array}{l}\text { Parents together } \\
\qquad(\mathrm{N}=53)\end{array}$ & $10.94(4.72)$ & $27.33(7.45)$ & $11.92(8.18)$ & 18.00 & $8.46(4.67)$ & $12.10(3.46)$ & $23.40(11.13)$ & $9.40(3.28)$ \\
\hline \multirow{2}{*}{$\begin{array}{l}\text { Girl with } \\
\text { sister }\end{array}$} & Parents split $(\mathrm{N}=77)$ & $13.06(4.37)$ & $27.18(8.34)$ & $12.03(5.40)$ & $18.56(4.28)$ & 11.89(6.55) & $8.51(9.90)$ & $23.34(9.24)$ & $10.49(6.10)$ \\
\hline & $\begin{array}{l}\text { Parents together } \\
\qquad(\mathrm{N}=51)\end{array}$ & $10.24(2.66)$ & 32.66 (5.98) & $8.75(6.86)$ & $21.18(3.48)$ & $10.21(7.44)$ & $15.27(7.14)$ & 35.36 (12.57) & $11.88(4.77)$ \\
\hline \multirow{2}{*}{$\begin{array}{l}\text { Boy with } \\
\text { both }\end{array}$} & Parents split $(\mathrm{N}=35)$ & $11.63(3.34)$ & $22.46(4.29)$ & $15.46(2.66)$ & 13.46 & $16.74(4.68)$ & $10.26(4.94)$ & $18.51(2.95)$ & $4.49(1.40)$ \\
\hline & $\begin{array}{l}\text { Parents together } \\
\qquad(\mathrm{N}=43)\end{array}$ & $16.63(8.19)$ & $20.26(5.16)$ & $10.81(6.93)$ & $12.56(4.51)$ & $10.59(7.14)$ & $7.56(9.11)$ & $25.53(7.51)$ & 9.88 (3.53) \\
\hline \multirow{2}{*}{$\begin{array}{l}\text { Girl with } \\
\text { both }\end{array}$} & Parents split $(\mathrm{N}=61)$ & $14.77(8.83)$ & $24.85(5.51)$ & $11.59(4.71)$ & 15.77 & $13.73(6.72)$ & 9.59 (4.68) & 21.57 (4.35) & 7.43 (3.81) \\
\hline & $\begin{array}{l}\text { Parents together } \\
\qquad(\mathrm{N}=69)\end{array}$ & $14.10(5.65)$ & $25.57(5.02)$ & $8.48(4.79)$ & $13.36(2.80)$ & $11.62(5.29)$ & $8.19(4.70)$ & $30.32(9.44)$ & $11.46(5.37)$ \\
\hline
\end{tabular}


ment Scale consists of ten first order factors which then combine to form the three second order factors used in the analysis so far, it was felt appropriate at this stage to look at the first order factors. These were cohesion, intellectual/cultural orientation, control, organisation, expressiveness, conflict, achievement orientation, religious/ moral orientation, independence, and active/recreational orientation. The analysis used manova with sibling gender structure and intact /broken homes as the independent variables. There were significant main effects of sibling gender structure for all variables: cohesion $(\mathrm{F}(7,700)=12.10, p<.001)$, intellectual/cultural orientation $(\mathrm{F}(7,700)=16.48, p<.001)$, control $(\mathrm{F}(7,700)=6.97, p<.001)$, organisation $(\mathrm{F}(7,700)=5.69, p<.001)$, expressiveness $(\mathrm{F}(7,700)=16.90, p<.001)$, conflict $(\mathrm{F}(7,700)=2.52, p<.01)$, achievement orientation $(\mathrm{F}(7,700)$ $=15.07, p<.001)$, religious/moral orientation $(\mathrm{F}(7,700)=5.23, p<.001)$, independence $(\mathrm{F}(7,700)=15.54, p$ $<.001)$, and active/recreational orientation $(\mathrm{F}(7,700)=5.53, p<.001)$. In line with the results for the second order FES factors boys with sisters and girls with sisters score higher on cohesion, expressiveness, and achievement orientation, and lower on conflict. Girls with sisters score highest on independence and active recreational orientation.

There were significant main effects of intact/broken homes on cohesion $(\mathrm{F}(1,706)=69.85, p<.001)$, intellectual/cultural orientation $(\mathrm{F}(1,706)=24.98, p<.001)$, control $(\mathrm{F}(1,706)=24.21, p<.001)$, organisation $(\mathrm{F}(1$, $706)=44.01, p<.001)$, expressiveness $(\mathrm{F}(1,706)=9.15, p<.001)$ achievement orientation $(\mathrm{F}(1,706)=10.48$, $p<.001)$, religious/moral orientation $(\mathrm{F}(1,706)=159.78, p<.001)$, independence $(\mathrm{F}(1,706)=37.59, p<.001)$, and active/recreational orientation $(\mathrm{F}(1,706)=44.14, p<.001)$. Participants from intact homes scored higher on cohesion, control, organisation, religious/moral orientation, independence, and active recreational orientation.

There were significant interactions between sibling gender structure and intact/broken homes on cohesion $(\mathrm{F}(7,700)=16.90, p<.001)$, intellectual/cultural orientation $(\mathrm{F}(7,700)=16.90, p<.001)$, control $(\mathrm{F}(7,700)=$ 16.90, $p<.001)$, organisation $(\mathrm{F}(7,700)=16.90, p<.001)$, expressiveness $(\mathrm{F}(7,700)=16.90, p<.001)$, conflict $(\mathrm{F}(7,700)=16.90, p<.001)$, achievement orientation $(\mathrm{F}(7,700)=16.90, p<.001)$, religious/moral orientation $(\mathrm{F}(7,700)=16.90, p<.001)$, independence $(\mathrm{F}(7,700)=16.90, p<.001)$, and active/recreational orientation $(F(7,700)=16.90, p<.001)$. The findings here are generally consistent with the findings for the second order factors of the FES but it is important to comment on the factors that make up the second order factor personal growth. The means for the factors making up this dimension are shown in Table 2. Boys with sisters and girls with sisters score equally high on achievement orientation and independence but do not score highest on religious moral orientation or active recreational orientation. Since these four factors are totalled to make personal growth these differences probably mask the positive effect of having a sister on the personal growth dimension.

\section{Discussion}

In the introduction to this paper three research questions were outlined which this study aimed to address. The first question concerns whether the gender structure of siblings in the family impacts upon later health, and requires a closer look at the main effect of sibling structure on psychological distress. Initial analysis showed that participants with a brother experienced the most psychological distress. Further analysis, whereby the sex of the participant was also considered, showed boys with brothers to be the most psychologically distressed. Girls with brothers were shown to be the second highest on the psychological distress variable, closely followed by both boys and girls with both brothers and sisters. The participants with the lowest levels of psychological distress were boys and girls with sisters. It would therefore appear that, for psychological distress at least, the sex of the participants themselves is less important than the gender of the siblings. It is the latter which affects the participants' levels of psychological distress, with female siblings having a positive effect, and male siblings a negative effect. The literature suggests that male siblings both increase the level of conflict and lower the level of cohesion within the sibling relationship (Weiss, Schitaffino, \& Ilowite, 2001). As sibling support is considered to be an important source of social support during family problems (Dunn, 1996) it would logically follow that female siblings would provide more support than male siblings, and that it is via this mediating variable that the sex of siblings impacts upon health. This was the second aim of the study i.e. to investigate in what way the gender structure of siblings is related to psychological or physical health as an adult.

In order to assess the mechanisms by which sibling gender structure affects distress levels it was considered prudent to measure the effect of sibling sex upon known mediators of psychological distress. The mediating variables included in this study (social support, locus of control, optimism, and pessimism) have been consis- 
tently identified in the literature as mediating or moderating psychological distress and therefore psychological health (e.g. Sarason, Sarason \& Pierce, 1993; Krause \& Stryker, 1984; Cassidy, 1999). In the case of social support the participants with the highest scores and therefore the highest levels of perceived social support were girls with sisters, followed by boys with sisters. The participants with the lowest levels of perceived support were boys and girls with brothers. These results suggest that whilst girls generally have higher levels of perceived support this is not the case when the girl in question has a male sibling only. For the male participants those with a sister had the highest level of support, followed by boys with no siblings. Similarly for the variable optimism the participants with the highest scores, and therefore the most optimistic participants, were girls with sisters, followed by boys with sisters. The least optimistic participants were both girls and boys with brothers only. These findings suggest that the presence of a male sibling without the apparent mediating presence of a female sibling leads to low levels of perceived social support and optimism for both girls and boys. This finding regarding social support is perhaps not surprising when one considers that sibling relationships involving a male sibling have been found to have less cohesion (Weiss et al., 2001) and therefore more negativity (Brody, Stoneman, \& McCoy, 1994) possibly resulting in less support.

The participants with the strongest internal locus of control were boys with sisters and boys with both brothers and sisters. A possible explanation for this could be that boys with siblings (particularly those with sisters) feel protective of their siblings, increasing their perception of control resulting in a strong internal locus of control. Both boys and girls with only brothers had a stronger external locus of control. Interestingly the participants with the strongest external locus of control were boys without any siblings. This finding indicates that, as with social support and optimism, it is not the sex of the participant that affects their locus of control (as boys had both the strongest internal and external locus of control) but the sex of their siblings. This same pattern occurs with the family environment dimensions of family relationship (where girls had both the highest and the lowest scores) and systems maintenance.

In the current study then, it was found that the gender structure of siblings in the family does indeed impact upon later health. The next logical step was to see if the presence of siblings, and indeed the gender of these siblings, mediates or moderates the impact of a broken home upon later health as a young adult. Levels of psychological distress were found to be consistently higher for those participants from a broken home as expected (Cherlin, Kiernan, \& Chase-Lansdale, 1995) except for only children (of either sex), boys with sisters, and boys with both brothers and sisters. This finding suggests that, at least in the case of boys, siblings can mediate the impact of a broken home upon psychological distress. However the fact that the highest levels of psychological distress were observed in boys with brothers from broken homes indicates that this is only the case when at least one of the siblings is female.

The above pattern is replicated, although reversed, in the case of pessimism. In fact it would appear from the results that the mere presence of any siblings increases a person's levels of pessimism! The lowest scores for pessimism were boys with sisters, followed by both boys and girls without any siblings. On the other hand the highest scores were achieved by both boys and girls with brothers. It was also found that boys and girls with sisters had lower levels of pessimism than participants with both brothers and sisters, suggesting that the mere presence of a male sibling increases levels of pessimism. This finding still stands when family background is included in the analysis. This means that in the case of pessimism, rather than siblings mediating the impact of a broken home they increase levels of pessimism, particularly when one of the siblings is male.

Of the participants from broken homes the highest social support scores were for boys and girls with sisters, and only children (of either sex). The lowest scores were for boys with brothers, followed by boys with both brothers and sisters, intimating that the presence of a male sibling, for boys at least, results in decreased social support levels. This supports the findings of previous studies whereby female siblings were found to be associated with more expressive family environments than males (Cassidy \& Newport, 1996) and sibling relationships were identified as being an important source of support during family transitions (Bryant, 1992; Dunn, 1996). What cannot be assumed from these findings however, is the mechanism by which female siblings increase levels of perceived social support. It is possible that the female siblings themselves provided participants with higher levels of social support than male siblings. However, it is equally possible that, as sibling relationships "lay the groundwork for developing relationships" (Bank \& Kahn, 1976) and female siblings encourage expression, the participants with female siblings have higher levels of social support not because they are including their female siblings, but because participants with female siblings have adjusted better socially.

This second order factor of the family environment scale consisted of three first order factors; cohesion, con- 
flict and expressiveness. Findings from previous literature meant expectations were for participants with sisters to score higher on cohesion and expressiveness and lower on conflict (Weiss et al., 2001; Cassidy \& Newport, 1996). Indeed, following parental separation, boys and girls with sisters reported high levels of cohesion, whilst the lowest levels were reported by girls with brothers. The highest levels of conflict were reported by both boys and girls with brothers. And, although girls generally reported higher levels of expression, the highest levels of expression were reported by both boys and girls with sisters and only girls. It appears that the presence of female siblings has a positive impact upon the family environment which, in turn, has a positive impact upon a person's health, reducing the detrimental effect of parental separation.

Research in this area has tended to pay lip service to the impact of inter-sibling relationships. This research suggests that these relationships are of equal importance to parental relationships. The fact that this area is under researched is perhaps due to the complex nature of family environments and family structure and while this study by no means addresses all the issues it does highlight a number of interesting relationships. Clearly the addition of some qualitative methods such as semi-structured interviews would allow a more in depth understanding of the complex environment and relationships previously mentioned. Some of the debate regarding the impact of non-intact homes has lacked the understanding that can be provided by this type of research. The simplistic stereotypes that still exist are damaging to individuals from a non-traditional family background. Unfortunately these stereotypes have in the past informed policy and practice in social services thereby reinforcing the same stereotypes. The purpose of this area of research is therefore to inform both the debate concerning the social and psychological consequences of changes in family situations and the programmes and techniques designed to improve parenting and family support services.

\section{Conclusion}

The psychological consequences of family trauma particularly when families break up, are of concern in terms of the health and well-being of children. Of particular interest to those who work with families are the risk and protective factors which can become the target for intervention. This study suggests that family relations as measured by expressiveness, cohesion and conflict are protective factors and these are engendered by the presence of sisters in the family constellation. The converse is that the presence of brothers tends to reduce expressiveness and cohesion and is more likely to lead to negative consequences. The recommendation is that those working with families should be aware of the communication processes following trauma and in particular where the natural expressiveness of females can be enhanced and the reticence of boys can be targeted.

\section{References}

Amato, P. R., Loomis, L. S., \& Booth, A. (1995). Parental Divorce, Marital Conflict, and Offspring Wellbeing during Early Adulthood. Social Forces, 83, 895-915. http://dx.doi.org/10.1093/sf/73.3.895

Bank, S. P., \& Kahn, M. D. (1976). Sisterhood-Brotherhood Is Powerful: Sibling Subsystems and Family Therapy. Family Process, 14, 311-337. http://dx.doi.org/10.1111/j.1545-5300.1975.00311.x

Biblarz, T., \& Raftery, A. (1999). Family Structure, Educational Attainment, and Socioeconomic Success: Rethinking the "Pathology of Matriarchy". American Journal of Sociology, 105, 321-365. http://dx.doi.org/10.1086/210314

Brody, G. H., Stoneman, Z., \& McCoy, J. K. (1994). Contributions of Family Relationships and Child Temperament to Longitudinal Variations in Sibling Relationship Quality and Sibling Relationship Styles. Journal of Family Psychology, 8, 274-286. http://dx.doi.org/10.1037/0893-3200.8.3.274

Brown, J. R., \& Dunn, J. (1992). Talk with Your Mother or Your Sibling? Developmental Changes in Early Family Conversations about Feelings. Child Development, 63, 336-349. http://dx.doi.org/10.2307/1131483

Cassidy, T., \& Newport, S. (1996) Family Structure, Environment and Achievement Motivation. BPS London Conference.

Cassidy, T., \& Burnside, E. (1996). Cognitive Appraisal, Vulnerability and Coping: An Integrative Analysis of Appraisal and Coping Mechanisms. Counselling Psychology Quarterly, 9, 261-279.

http://dx.doi.org/10.1080/09515079608258707

Cassidy, T. (1999). Stress, Cognition and Health. London: Routledge.

Cherlin, A. J., Kirnan, K. E., \& Chase-Lansdown, P. L. (1995). Parental Divorce in Childhood and Demographic Outcomes in Young Adulthood. Demography, 32, 299-318. http://dx.doi.org/10.1080/09515079608258707

Craig, A. R., Franklin, J. A., \& Andrews, G. (1984). A Scale to Measure Locus of Control of Behaviour. British Journal of Medical Psychology, 57, 173-180. http://dx.doi.org/10.1111/j.2044-8341.1984.tb01597.x 
Dunn, J. (1996). Brothers and Sisters in Middle Childhood and Early Adolescence: Continuity and Change in Individual Differences. In G. H. Brody (Ed.), Sibling Relationships: Their Causes and Consequences (pp. 125-138). Westport, CT: Ablex Publishing.

Goldberg, D. (1972). The Detection of Psychiatric Illness by Questionnaire. London: Oxford University Press.

Krause, N., \& Stryker, S. (1984). Stress and Well-Being: The Buffering Role of Locus of Control Beliefs. Social Science and Medicine, 18, 783-790. http://dx.doi.org/10.1016/0277-9536(84)90105-9

Moos, R. H., \& Moos, B. S. (1986). Family Environment Scale Manual (2nd ed.). Palo Alto, CA: Consulting Psychologists Press.

Pretorius, T. B., \& Diedricks, M. (1994). Problem Solving Appraisal, Social Support and Stress-Depression Relationship. South African Journal of Psychology, 24, 86-91. http://dx.doi.org/10.1177/008124639402400206

Scheier, M. F., \& Carver, C. S. (1985). Optimism, Coping, and Health: Assessment and Implications of Generalised Outcome Expectancies. Health Psychology, 4, 219-247. http://dx.doi.org/10.1037/0278-6133.4.3.219

Stormshak, E. A., Bellanti, C., \& Bierman, K. L. (1996). The Quality of Sibling Relationships and the Development of Social Competence and Behavioural Control in Aggressive Children. Developmental Psychology, 32, 79-89. http://dx.doi.org/10.1037/0012-1649.32.1.79

Videon, T. M. (2002). The Effects of Parent-Adolescent Relationships and Parental Separation on Adolescent Well-Being. Journal of Marriage and Family, 64, 489-503. http://dx.doi.org/10.1111/j.1741-3737.2002.00489.x

Weiss, K. A., Schiaffino, K. M., \& Ilowite, N. (2001). Predictors of Sibling Relationship Characteristics in Youth with Juvenile Chronic Arthritis. Children’s Health Care, 30, 67-77. http://dx.doi.org/10.1207/S15326888CHC3001_6 
Scientific Research Publishing (SCIRP) is one of the largest Open Access journal publishers. It is currently publishing more than 200 open access, online, peer-reviewed journals covering a wide range of academic disciplines. SCIRP serves the worldwide academic communities and contributes to the progress and application of science with its publication.

Other selected journals from SCIRP are listed as below. Submit your manuscript to us via either submit@scirp.org or Online Submission Portal.
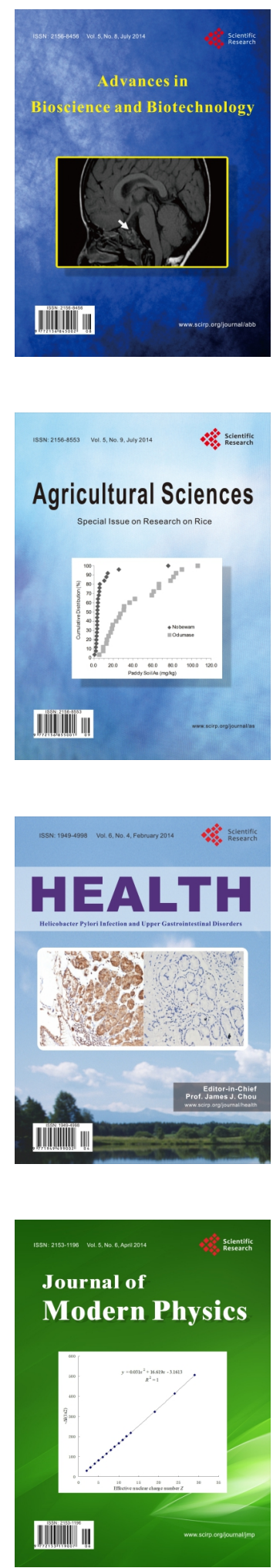
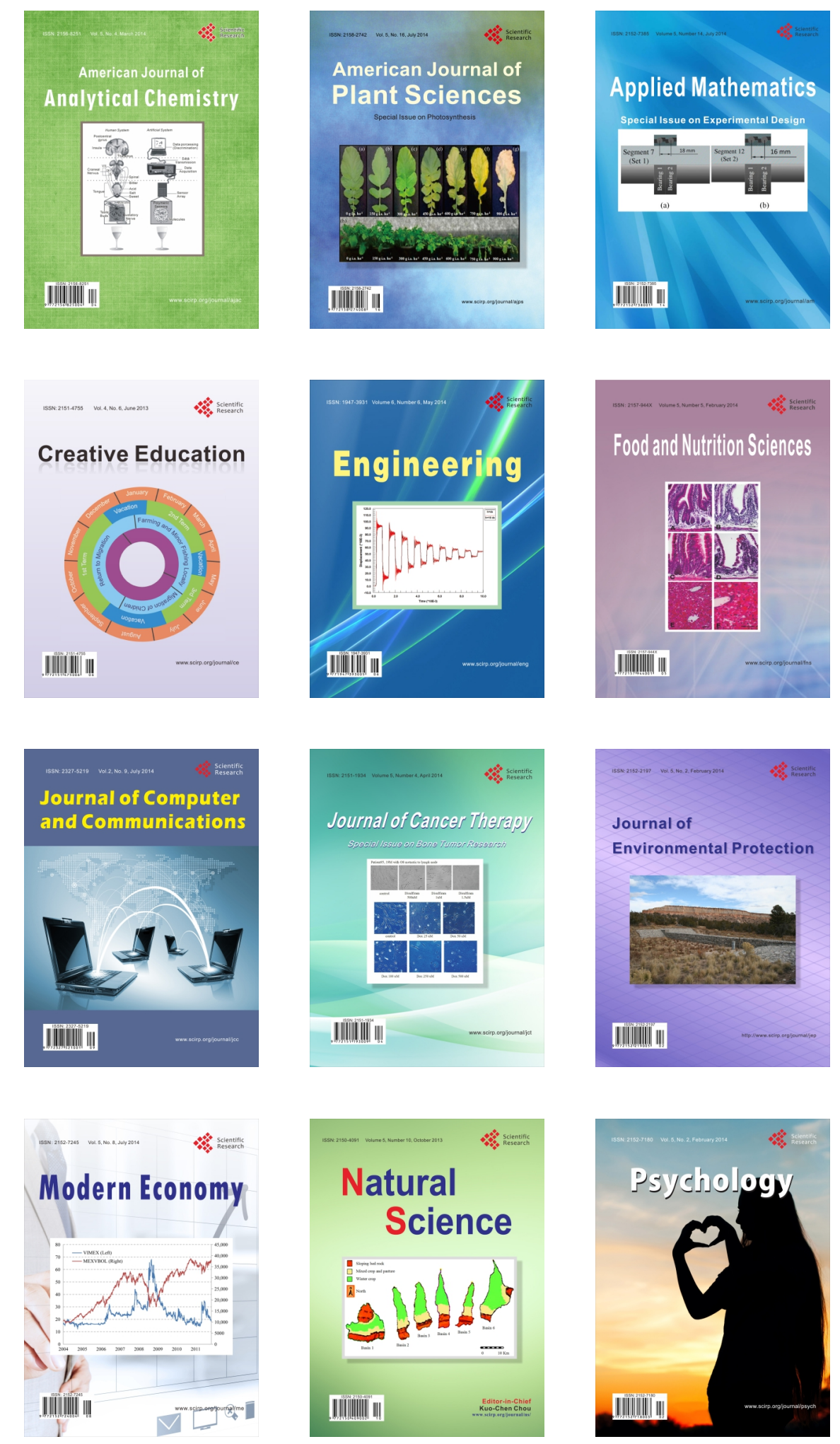